\title{
Ocular tuberculosis in a calf.
}

\author{
Jacobo Carrisoza-Urbina', Mario A. Bedolla-Alva², Mireya Juárez-Ramírez² and José A. Gutiérrez-Pabello1*
}

\begin{abstract}
Background: Bovine tuberculosis is a chronic inflammatory disease that causes granuloma formation mainly in retropharyngeal, tracheobronchial, mediastinal lymph nodes and lungs of bovines. The presence of these lesions in other tissues such as the eyeball is very rare and difficult to diagnose. This study describes macroscopic and microscopic pathological findings in a calf with ocular and meningeal tuberculosis.

Case presentation: March 2019, an eight-month-old Holstein Friesian calf was identified in a dairy farm located in central Mexico with a clinical cough, anorexia, incoordination, corneal opacity and vision loss. At necropsy, pneumonia, lymphadenitis, meningitis, and granulomatous iridocyclitis were observed. The histopathological examination revealed granulomatous lesions in lung tissue, lymph nodes, meninges and eyes with the presence of acid-fast bacilli associated with Mycobacterium spp.

Conclusion: To the best of our knowledge, this is the first report that describes macroscopic and microscopic pathological findings of ocular tuberculosis in cattle. This report highlights the importance of considering bovine tuberculosis in the differential diagnosis of corneal opacity and loss of vision in cattle.
\end{abstract}

Keywords: Bovine tuberculosis, Meningeal tuberculosis, Ocular tuberculosis, Ocular granuloma

\section{Background}

Presence of extrapulmonary tuberculosis in humans in industrialized countries has increased from $16 \%$ in 1993 to $21 \%$ in 2006 [1]. The most lethal of these presentations is meningeal tuberculosis with an estimate of more than 100,000 cases per year [2]. Central nervous system involvement is a factor for the development of ocular tuberculosis, a very rare presentation in the population [3]. Likewise, cases of ocular tuberculosis in natural infections in animals are limited. Among the species susceptible to tuberculosis are cattle affected by Mycobacterium bovis (M. bovis) with a high prevalence in different parts of the world, showing similarities in immunopathology with tuberculosis in humans, which highlights the importance of this species as a model for studying ocular presentation [4-8]. Bovine tuberculosis

\footnotetext{
* Correspondence: jagp@unam.mx

'Laboratorio de Investigación en Tuberculosis Bovina, Departamento de Microbiología e Inmunología, Facultad de Medicina Veterinaria y Zootecnia, Universidad Nacional Autónoma de México, Mexico city, Mexico Full list of author information is available at the end of the article
}

frequently causes granulomatous lesions in the retropharyngeal, tracheobronchial, mediastinal lymph nodes, and lungs of cattle. Other less frequently affected organs are the regional lymph nodes, spleen, liver, kidney, intestine, mesenteric lymph nodes, vertebrae, and spinal cord. However, ocular involvement has rarely been reported $[6,8]$. In this case report we present for the first time the macroscopic and microscopic pathological description of ocular tuberculosis in a calf.

\section{Case presentation}

An eight-month-old Holstein Friesian calf from a stable with 220 cattle located in a complex of approximately 28,000 dairy cattle, with an intensive production system in the central area of Mexico, presented cough, anorexia, incoordination and loss of vision. The calf was referred to the Centro de Enseñanza y Diagnóstico en Enfermedades de los Bovinos of the Facultad de Medicina Veterinaria y Zootecnia at Universidad Nacional Autónoma de México, where the post mortem examination was performed. Bovines from this stable had previously been 


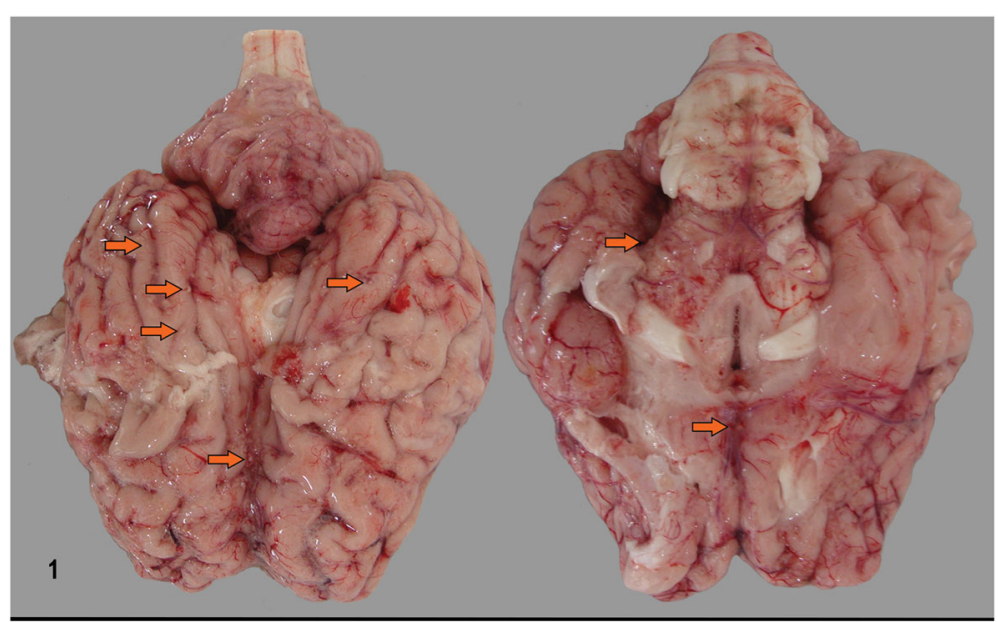

Fig. 1 Meningeal tuberculosis in a bovine. Bovine brain with multifocal nodular granulomas in the meninges indicated by arrows

identified with lesions compatible with bovine tuberculosis.

Body inspection at necropsy revealed a carcass with pale conjunctival and oral mucosa. On internal inspection, the cranial, intermediate, accessory, and cranioventral lobes of the lungs were hyperemic and consolidated. The mediastinal lymph nodes were enlarged and extensive areas of yellow foci with granulomatous inflammation and a central core of caseous necrosis were identified. The leptomeninges presented many white nodules corresponding to granulomas in the cerebral hemispheres located mainly at the base of the brain (Fig. 1). Corneal opacity was observed in both eyes, the ciliary processes show thickening with nodular coalescing granulomas (Fig. 2).

Tissue segments from brain, eye, lymph node, and lung were fixed in 10\% formaldehyde and paraffinembedded for routine histological staining. A granulomatous inflammatory infiltrate was observed in the leptomeninges, mainly composed of macrophages, epithelioid macrophages, and lymphocytes. In some areas, granulomas were identified with necrotic center, surrounded by epithelioid macrophages, abundant multinucleated giant cells, interspersed with lymphocytes, plasma cells and few fibroblasts; some lesions contain central mineralization surrounded by numerous epithelioid macrophages (Fig. 3a). Bacilli were identified in areas with necrosis and in the cytoplasm of macrophages by Ziehl Neelsen (ZN) staining and immunohistochemistry (Figs. 3b and 4). The eyeball showed normal anatomic loss at the level of the lens, which was replaced by granulomatous lesions with similar characteristics as the lesions found in the meninges, showing rare neutrophils and a greater amount of connective tissue around the lesions. The choroid showed multifocal granulomas with acid fast bacilli in the macrophage cytoplasm and central mineralization identified by Von Kossa stain (Fig. 5a and b). In the mediastinal lymph nodes and lungs, granulomatous lesions with the characteristics previously described were also identified.

PCR using template DNA extracted from formalinfixed paraffin-embedded (FFPE) tissues that had histopathological lesions compatible with tuberculosis was performed [9]. We used a universal set of primers

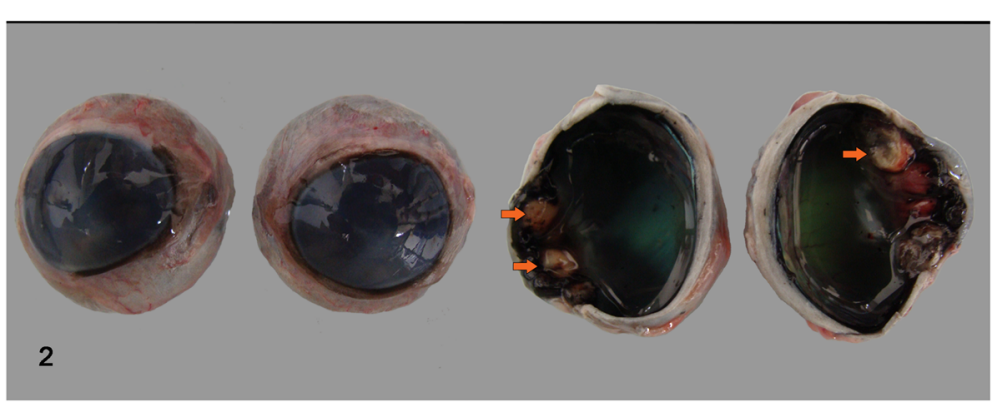

Fig. 2 Ocular tuberculosis in a bovine. Corneal opacity in both eyes. Cross section of the eye shows anterior uvea thickening with nodular yellow coalescing granulomas indicated by arrows 


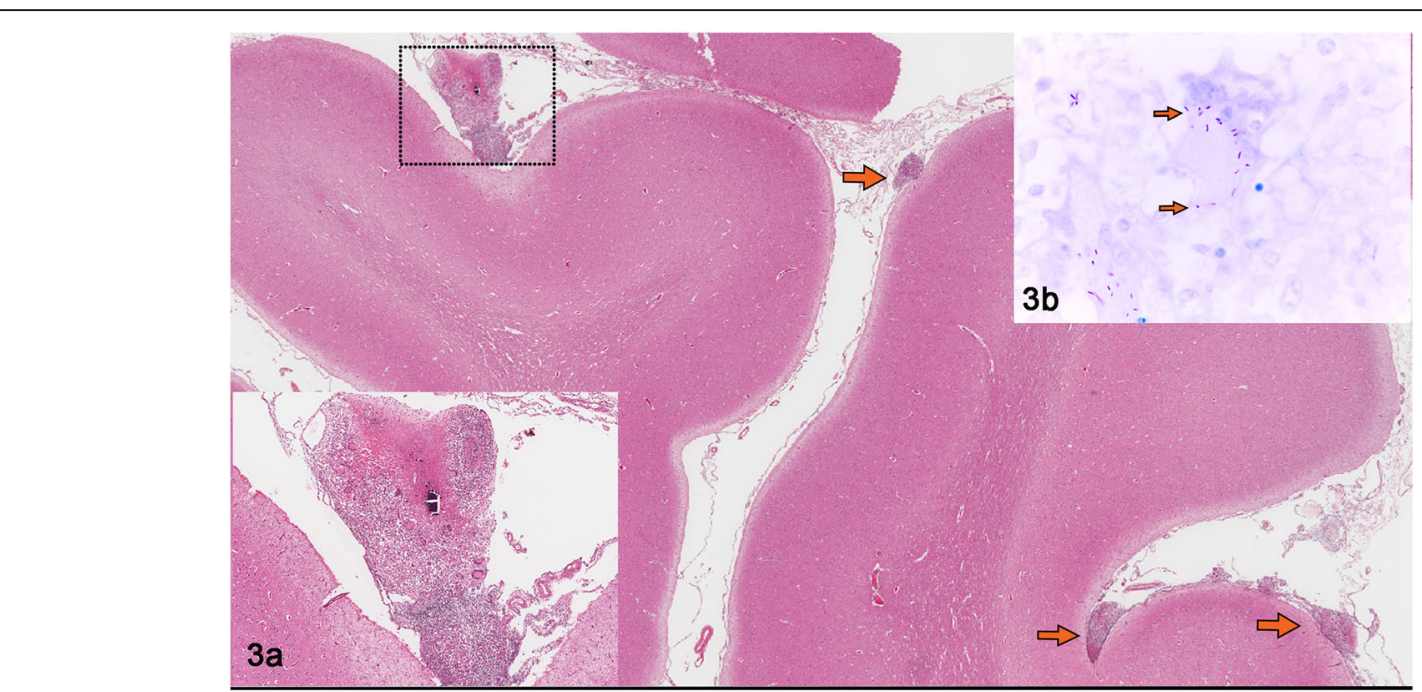

Fig. 3 a Granulomas multifocal to coalescing in meningeal tuberculosis cause by Mycobacterium spp. in a bovine. a Section of the brain shows a granulomatous inflammatory infiltrate in the meninges indicated by arrows. The close-up shows a granuloma composed of numerous epithelioid macrophages and multinucleated giant cells, a necrotic area with mineralization and a thin fibrous connective tissue capsule. b Ziehl Neelsen stain shows acid fast bacilli indicated by arrows

spanning for V1-V3 short variable regions of the bacterial $16 \mathrm{~S}$ rRNA gene that amplify a product of $\sim 500 \mathrm{bp}$. A nested PCR for mpb70/m22 genes was used to identify members of the Mycobacterium tuberculosis complex, a positive result produces amplicons of $372 \mathrm{bp}$ and $208 \mathrm{bp}$ of length, respectively. In addition, an endpoint PCR of the RD9 with a product of $333 \mathrm{bp}$ for Mycobacterium tuberculosis (M. tuberculosis) and 206 bp for M. bovis was

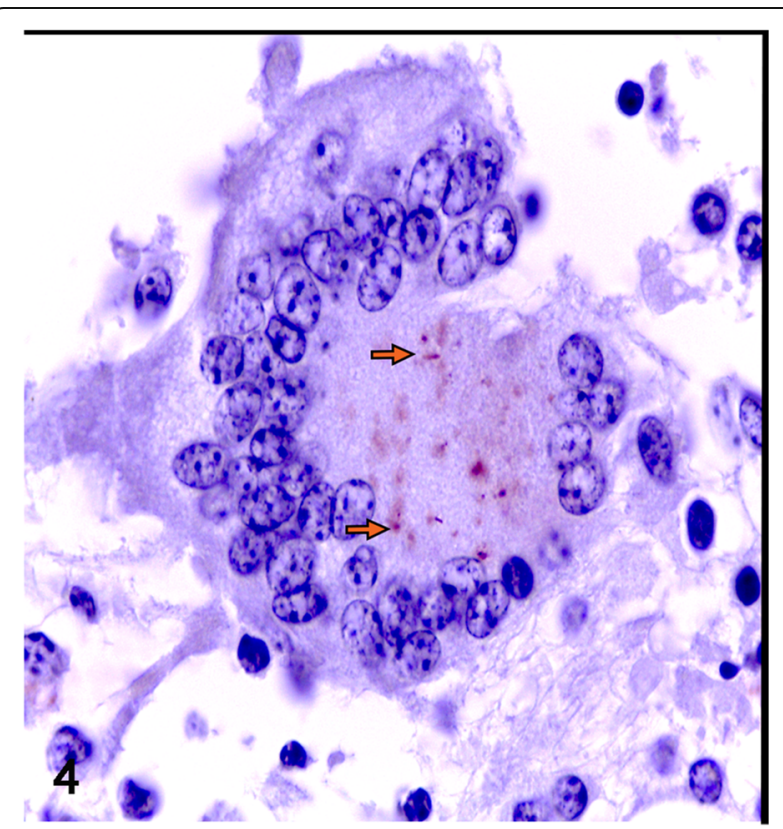

Fig. 4 Immunohistochemistry of Mycobacterium tuberculosis. Shows a giant cell with cytoplasmic bacilli indicated by arrows in a section of the meninges performed. Finally, the RD4 gene was used to amplify a product of $268 \mathrm{bp}$ for $M$. bovis and $172 \mathrm{bp}$ for the rest of the members of the Mycobacterium tuberculosis complex. All primer sequences used are described in Table 1. Electrophoresis in a $2 \%$ agarose gel with SYBR Green (S9430 SIGMA-ALDRICH) was used for separated the products of DNA and next were visualized using a photo documenter (Gel Logic 200 Imaging System, Kodak, UK). Unfortunately, despite carrying out the different PCR protocols, it was not possible to obtain amplifications from the tissues of this case.

\section{Discussion and conclusions}

According to the macroscopic findings at necropsy and laboratory tests performed, this case report describes a calf with bovine tuberculosis. The main finding was the presence of mycobacterial granulomatous lesions in the brain and both eyes. Although we attempted to identify the mycobacterium species by isolation or by polymerase chain reaction (PCR), all our efforts were negative. Therefore, we decided to use a polyclonal antibody against M. tuberculosis (biocare medical, CP 140) which cross reacts with members of the tuberculosis complex. Immunohistochemistry revealed a positive staining of mycobacterial antigens in the granulomatous lesions. Furthermore, $M$. bovis has previously been isolated in the calf herd and prevalence of bovine tuberculosis was greater than $16 \%$, altogether our results suggests $M$. bovis as the etiological agent $[14,15]$. The pathogenesis of ocular tuberculosis is unknown, until now it is believed that the spread of the bacteria originates from the primary site of infection to the eyeball by hematogenous 


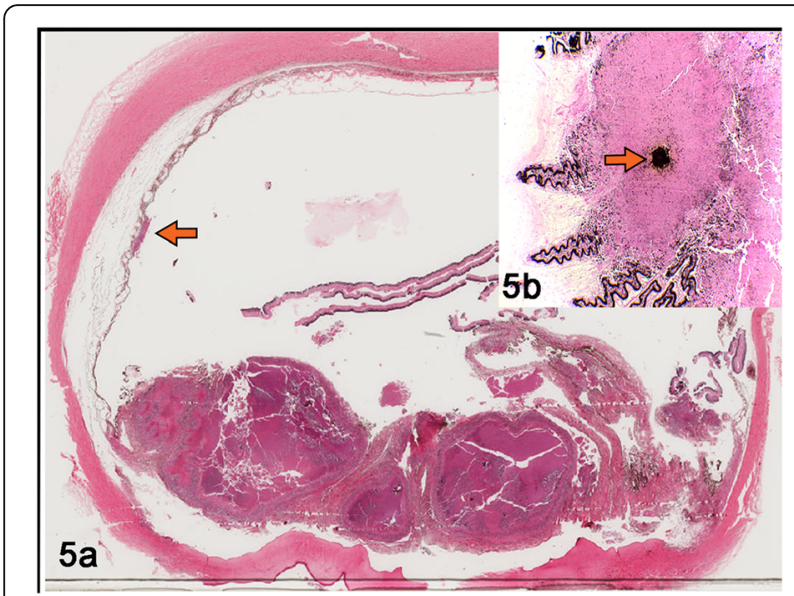

Fig. 5 a Granulomas multifocal to coalescing in ocular tuberculosis cause by Mycobacterium spp. in a bovine. a Iris and ciliary body show coalescent granulomas with a thick capsule of connective tissue. The choroid shows mild granulomatous inflammation indicated by arrows. b Von Kossa stain shows mineralization in a granuloma indicated by arrows

route, frequently presenting granulomas in the choroid [8]. Endogenous infection of the eyeball by M. bovis has been identified in adults or immunocompetent people $[16,17]$. Likewise, this affectation was reported in $3.2 \%$ $(9 / 282)$ of patients who presented disseminated tuberculosis when receiving immunotherapy with Bacillus Calmette-Guérin (BCG) as a treatment for bladder cancer, causing uveitis, endophthalmitis and autoimmune retinopathy. This presentation differs from destructive intraocular tuberculosis caused by M. tuberculosis, which mainly originates choroidal granulomas and subretinal abscesses $[18,19]$.

Study of ocular tuberculosis in naturally infected animals will provide a better understanding of bovine tuberculosis pathogenesis. This report highlights the

Table 1 The primers and sequencing used for PCR

\begin{tabular}{lll}
\hline Primers & Sequence $\left(\mathbf{5}^{\prime} \rightarrow \mathbf{3}^{\prime}\right)$ & Reference \\
\hline 16S-F & TTGGAGAGTTGATCMTGGCTC & {$[10]$} \\
16S-R & GTATTACCGCGGCTGCTG & \\
MPB70-F & GAACAATCCGGAGTTACAA & {$[11]$} \\
MPB70-R & AGCACGCTGTCAATCATGTA & \\
M22-F & GAACAATCCGGAGTTACAA & {$[11]$} \\
M22-R & CGTTGGCCGGCTGGTTGGCC & \\
RD9- F & GTGTAGGTCAGCCCCATCC & {$[12]$} \\
RD9-I & CAATGTTTGTGCGCTGC & \\
RD9 -R & GCTACCCTCGACCAAGTGT & \\
RD4-F & ATGTGCGAGCTGAGCGATG & {$[13]$} \\
RD4-I & TGTACTATGCTGACCCATGCG & \\
RD4-R & AAAGGAGCACCATCGTCCAC & \\
\hline
\end{tabular}

importance of considering bovine tuberculosis in the differential diagnosis of corneal opacity and loss of vision in cattle.

\section{Abbreviations}

FFPE: Formalin-fixed paraffin-embedded; HE: Hematoxylin and eosin staining method; PCR: Polymerase chain reaction; ZN: Ziehl-Neelsen staining method

\section{Acknowledgements}

We wish to thank Karen J. Guitareo Quintana for their help with histological procedures and like to thank Sara Huerta Yepez for providing access to the Aperio ScanScope ${ }^{\oplus}$ scan microscope.

\section{Authors' contributions}

MABA: Responsible for the necropsy and macroscopic description. MABA MJR and JCU: Microscopic description of the lesions. JCU and MJR: performance of immunohistochemistry. JCU and JAGP: Analysis of laboratory results and were major contributors in writing the manuscript. All authors read and approved the final manuscript.

\section{Funding}

This work was supported by grant PAPIIT AG-200918 from Universidad Nacional Autónoma de México. The funder had no role in the design of the study, data collection, analyses, interpretation of data, decision to publish, or preparation of the manuscript.

\section{Availability of data and materials}

The datasets used and/or analysed during the current study are available from the corresponding author on reasonable request.

\section{Declarations}

Ethics approval and consent to participate

Not applicable.

\section{Consent for publication}

Not applicable.

\section{Competing interests}

The authors declare that they have no competing interests.

\section{Author details}

${ }^{1}$ Laboratorio de Investigación en Tuberculosis Bovina, Departamento de Microbiología e Inmunología, Facultad de Medicina Veterinaria y Zootecnia, Universidad Nacional Autónoma de México, Mexico city, Mexico.

${ }^{2}$ Departamento de Patología, Facultad de Medicina Veterinaria y Zootecnia, Universidad Nacional Autónoma de México, Mexico city, Mexico.

Received: 5 March 2021 Accepted: 29 April 2021

Published online: 08 May 2021

\section{References}

1. Thayil SM, Albini TA, Nazari H, Moshfeghi AA, Parel J-MA, Rao NA, et al. Local ischemia and increased expression of vascular endothelial growth factor following ocular dissemination of Mycobacterium tuberculosis. PLoS One. 2011;6:e28383. https://doi.org/10.1371/journal.pone.0028383.

2. Wilkinson RJ, Rohlwink U, Misra UK, Van Crevel R, NTH M, Dooley KE, et al. Tuberculous meningitis. Nat Rev Neurol. 2017;13:581-98. https://doi.org/10.1 038/nrneurol.2017.120.

3. Basu S, Monira S, Modi RR, Choudhury N, Mohan N, Padhi TR, et al. Degree, duration, and causes of visual impairment in eyes affected with ocular tuberculosis. J Ophthalmic Inflamm Infect. 2014;4:1-5. https://doi.org/10.11 86/1869-5760-4-3.

4. Stavinohova R, O'Halloran C, Newton JR, Oliver JAC, Scurrell E, Gunn-Moore DA. Feline ocular Mycobacteriosis: clinical presentation, histopathological features, and outcome. Vet Pathol. 2019;56:749-60. https://doi.org/10.1177/ 0300985819844819.

5. Gunn-Moore DA, McFarland SE, Brewer Jl, Crawshaw TR, Clifton-Hadley RS, Kovalik M, et al. Mycobacterial disease in cats in Great Britain: I. culture results, geographical distribution and clinical presentation of 339 cases. J Feline Med Surg. 2011;13:934-44. https://doi.org/10.1016/j.jfms.2011.07.012. 
6. Silveira AM, Nascimento EM, Konradt G, Neto EGM, Driemeier D, Galiza GJN, et al. Tuberculosis of the central nervous system in cattle in Paraíba. Brazil Pesqui Vet Bras. 2018;38:2099-108. https://doi.org/10.1590/1678-5150-PVB5976.

7. Aroch I, Ofri R, Sutton GA. Ocular manifestations of systemic diseases. In: Slatter's fundamentals of veterinary ophthalmology: Elsevier Inc; 2008. p. 374-418. https://doi.org/10.1016/B978-072160561-6.50021-6.

8. Mitchell JL, Ganis L, Blacklock BT, Petrushkin H, Hope JC, Gunn-Moore DA. Ocular Tuberculosis: more than 'Of Mice and Men'. Ocul Immunol Inflamm. 2020;1:1. https://doi.org/10.1080/09273948.2020.1797116.

9. van Helden PD, Victor TC, Warren RM, van Helden EG. Isolation of DNA from Mycobacterium tuberculosis. In: Mycobacterium tuberculosis protocols. New Jersey: Humana Press; 2001. p. 019-30. https://doi.org/10.1385/1-59259-1477:019.

10. Edwards KJ, Logan JMJ, Langham S, Swift C, Gharbia SE. Utility of real-time amplification of selected $16 \mathrm{~S}$ rRNA gene sequences as a tool for detection and identification of microbial signatures directly from clinical samples. J Med Microbiol. 2012;61:645-52. https://doi.org/10.1099/jmm.0.041764-0.

11. Estrada-Chávez C, Otero FD, Díaz CA, Villegas-Sepúlveda N, González RP, Salazar DG. Concordancia de la PCR y métodos rutinarios para el diagnóstico de tuberculosis bovina. Vet México. 2004;35:225-36 http://new. medigraphic.com/cgi-bin/resumen.cgi?IDARTICULO=6869

12. Das S, Das SC, Verma R. Occurrence of RD9 region and 500 bp fragment among clinical isolates of Mycobacterium tuberculosis and Mycobacterium bovis. Microbiol Immunol. 2007;51:231-4. https://doi.org/10.1111/j.13480421.2007.tb03905.x

13. Warren RM, Gey van Pittius NC, Barnard M, Hesseling A, Engelke E, de Kock $M$, et al. Differentiation of Mycobacterium tuberculosis complex by PCR amplification of genomic regions of difference. Int J Tuberc Lung Dis. 2006; 10:818-22 http://www.ncbi.nlm.nih.gov/pubmed/16850559.

14. Carrisoza-Urbina J, Morales-Salinas E, Bedolla-Alva MA, Hernández-Pando R, Gutiérrez-Pabello JA. Atypical granuloma formation in Mycobacterium bovisinfected calves. PLoS One. 2019;14:e0218547. https://doi.org/10.1371/journal. pone.0218547.

15. Situación actual de Tuberculosis Bovina | Servicio Nacional de Sanidad, Inocuidad y Calidad Agroalimentaria | Gobierno | gob.mx. https://www.gob. $\mathrm{mx} /$ senasica/documentos/situacion-actual-de-tuberculosis-bovina?state= published. Accessed 25 Mar 2021.

16. Liesegang TJ, Cameron JD. Mycobacterium bovis infection of the conjunctiva. Arch Ophthalmol. 1980;98:1764-6. https://doi.org/10.1001/a rchopht.1980.01020040616004.

17. Sharma K, Gautam N, Sharma M, Dogra M, Bajgai P, Tigari B, et al. Ocular mycobacteriosis_-dual infection of $\mathrm{M}$ tuberculosis complex with $\mathrm{M}$ fortuitum and M bovis. J Ophthalmic Inflamm Infect. 2017;7:2. https://doi. org/10.1186/s12348-016-0121-0

18. Dammert P, Boujaoude Z, Rafferty W, Kass J. Fever of unknown origin and pancytopenia caused by culture-proven delayed onset disseminated bacillus Calmette-Guérin (BCG) infection after intravesical instillation. BMJ Case Rep. 2013;2013:1. https://doi.org/10.1136/bcr-2013-008949.

19. Asín MAPJ, Fernández-Ruiz M, López-Medrano F, Lumbreras C, Tejido A, Juan RS, et al. Bacillus Calmette-Guérin (BCG) infection following intravesical bcg administration as adjunctive therapy for bladder cancer incidence, risk factors, and outcome in a single-institution series and review of the literature. Medicine (United States). 2014;93:236-54. https://doi.org/10.1097/ MD.0000000000000119.

\section{Publisher's Note}

Springer Nature remains neutral with regard to jurisdictional claims in published maps and institutional affiliations.

Ready to submit your research? Choose BMC and benefit from:

- fast, convenient online submission

- thorough peer review by experienced researchers in your field

- rapid publication on acceptance

- support for research data, including large and complex data types

- gold Open Access which fosters wider collaboration and increased citations

- maximum visibility for your research: over $100 \mathrm{M}$ website views per year

At BMC, research is always in progress.

Learn more biomedcentral.com/submissions 